\title{
Successful treatment of aortic valve endocarditis caused by Enterococcus casseliflavus: a case report
}

\author{
Nobumasa Okumura ${ }^{1 *}$ D, Takashi Watanabe ${ }^{2}$, Satoshi Teranishi ${ }^{3}$, Daisuke Suzuki ${ }^{4}$, Takahiko Hashimoto ${ }^{1}$, \\ Kosuke Takahashi ${ }^{1}$ and Toru Hara ${ }^{1,4}$
}

\begin{abstract}
Background: Enterococcus casseliflavus is rarely isolated from human specimens. To the best of our knowledge, there are no reports on its detailed treatment course and prognosis. Here, we present the first known case of $E$. casseliflavus endocarditis with a detailed treatment course.

Case presentation: An 86-year-old Japanese woman was transferred to the emergency department with dyspnoea, wheezing, and lumbago. Her medical history included hypertension, chronic kidney disease, idiopathic interstitial pneumonia, and rectal carcinoma. Physical examination revealed expiratory wheezes and a diastolic murmur (Levine 2/6) at the 4th right sternal border. Chest radiography revealed bilateral interstitial opacities and slight cardiac dilatation. Transthoracic echocardiography demonstrated the presence of mobile vegetation with perforation, prolapse, and regurgitation of the aortic valve. With a suspicion of infective endocarditis, we started administering intravenous ampicillin/sulbactam. Thereafter, blood cultures identified E. casseliflavus through matrixassisted laser desorption/ionisation time-of-flight mass spectrometry. The antimicrobial treatment was then switched to ampicillin plus gentamicin. The patient underwent aortic valve replacement on the thirteenth hospital day. She was administered intravenous ampicillin and gentamicin for 6 weeks. The patient was discharged 8 weeks after admission.
\end{abstract}

Conclusions: Our case demonstrated that E. casseliflavus could cause infective endocarditis, which can be successfully treated with a 6-week regimen of ampicillin and gentamicin in combination with proper surgical treatment.

Keywords: Enterococcus casseliflavus, Enterococci, Infective endocarditis, Intrinsic resistance

\section{Background}

Enterococci are Gram-positive, facultatively anaerobic bacteria that are normal commensals of the human gastrointestinal tract [1]. However, they are known to cause hospital-associated infections such as bloodstream and urinary tract infections [1]. They also cause infective

\footnotetext{
* Correspondence: nobumasa730@gmail.com

'Department of Respiratory Medicine, Anjo Kosei Hospital, Anjo-cho Higashi-Hirokute 28, Anjo City, Aichi Prefecture, Japan

Full list of author information is available at the end of the article
}

endocarditis and are estimated to account for approximately $10 \%$ of cases of infective endocarditis [2]. E. faecalis and E. faecium are the major species isolated from clinical sources in patients with endocarditis. Among patients with enterococcal endocarditis, E. faecalis is the causative organism in $97 \%$ cases, E. faecium in 1 to $2 \%$, and other species in the remaining $1 \%$ [2]. E. casseliflavus, formerly known as Streptococcus faecium var. casseliflavus, was isolated for the first time in 1968 from a number of samples obtained from several plants [3]. E. casseliflavus was determined to be the

C C The Author(s). 2021 Open Access This article is licensed under a Creative Commons Attribution 4.0 International License, which permits use, sharing, adaptation, distribution and reproduction in any medium or format, as long as you give appropriate credit to the original author(s) and the source, provide a link to the Creative Commons licence, and indicate if changes were made. The images or other third party material in this article are included in the article's Creative Commons licence, unless indicated otherwise in a credit line to the material. If material is not included in the article's Creative Commons licence and your intended use is not permitted by statutory regulation or exceeds the permitted use, you will need to obtain permission directly from the copyright holder. To view a copy of this licence, visit http://creativecommons.org/licenses/by/4.0/ The Creative Commons Public Domain Dedication waiver (http://creativecommons.org/publicdomain/zero/1.0/) applies to the data made available in this article, unless otherwise stated in a credit line to the data. 
same species as E. flavescens and was subsequently referred to as E. casseliflavus/flavescens [4]. It is currently part of the E. gallinarum group along with E. gallinarum [5]. E. casseliflavus is rarely isolated from human clinical specimens. It is known to cause blood stream infection, meningitis, and endophthalmitis in humans [5]. However, to the best of our knowledge, there are few reports on infective endocarditis caused by E. casseliflavus, and there are no detailed reports on the treatment course used, such as antibiotic regimen, dose, duration, and surgical intervention. We report the first case of E. casseliflavus endocarditis with a detailed treatment course.

\section{Case presentation}

An 86-year-old Japanese woman was transferred to the emergency department with rapidly progressive dyspnoea and wheezing. She also reported a five-month history of lumbago. Her medical history included hypertension, chronic kidney disease, idiopathic interstitial pneumonia, and rectal carcinoma (resected). She had never undergone heart valve surgery or dental treatment. On examination, she was afebrile, and her blood pressure was $165 / 70 \mathrm{mmHg}$, pulse $88 / \mathrm{min}$, and respiratory rate $16 / \mathrm{min}$ with $\mathrm{O}_{2}$ saturation of $78 \%$ on room air. Physical examination was notable for expiratory wheezes and a diastolic murmur (Levine 2/6) at the 4th right sternal border. There was no evidence of rash or lumbar spine tenderness. Laboratory tests showed normocytic anaemia (haemoglobin level, $9.2 \mathrm{~g} / \mathrm{dL}$; mean cell volume, $91.5 \mathrm{fL}$ ), mild renal impairment (serum creatinine level $0.72 \mathrm{mg} / \mathrm{dL}$, Cockcroft-Gault CCr $39.1 \mathrm{~mL} / \mathrm{min}$ ), inflammation (C-reactive protein level $4.61 \mathrm{mg} / \mathrm{dL}$ ), and elevated brain natriuretic peptide level $(319.7 \mathrm{pg} / \mathrm{mL})$. Chest radiography revealed bilateral interstitial opacities, pleural effusion, and a slight cardiac dilatation (cardiothoracic ratio 64\%, Fig. 1a). Transthoracic echocardiography demonstrated the presence of mobile aortic vegetation $(9.5 \times 4.3 \mathrm{~mm}$ in size, Fig. $1 \mathrm{~b})$ with perforation, prolapse, and regurgitation of the aortic valve. Magnetic resonance imaging (MRI) of the lumbar region revealed destruction of the disc structure and adjacent vertebrae at the L3/4 level (Fig. 1c). A brain MRI showed no evidence of cerebral infarction or aneurysm.

Intravenous ampicillin/sulbactam, furosemide, and carperitide were administered based on a likely diagnosis of infective endocarditis, followed by pulmonary oedema and vertebral osteomyelitis. Gram-positive coccus, which was identified as E. casseliflavus through matrix-assisted laser desorption/ionisation time-of-flight mass spectrometry (MALDI-TOF MS; MALDI Biotyper, BRUKER, Billerica, MA, USA), was isolated from two sets of blood culture bottles on the day after admission. Soon after the causative microorganism became clear, we switched the antimicrobial regimen to ampicillin ( $3 \mathrm{~g}$ every $6 \mathrm{~h}$ ) and ceftriaxone ( $2 \mathrm{~g}$ every $12 \mathrm{~h}$, Fig. 2 ). Based on the broth microdilution method, the strain was susceptible to penicillin, ampicillin, and daptomycin (minimal inhibitory concentration $1,1,1 \mu \mathrm{g} / \mathrm{mL}$, respectively) according to the Clinical and Laboratory Standards Institute guidelines (M100-ED29). Although the minimal inhibitory concentration of vancomycin was $4 \mu \mathrm{g} / \mathrm{mL}$, the strain should be considered intrinsically resistant to vancomycin. Detection of $\operatorname{van} C$ gene was not performed, and susceptibility to oxazolidinones was not assessed. Given that no high-level resistance to gentamicin was detected with a screening test on agar plates (the diameter of the inhibition circle was $22 \mathrm{~mm}$ ), the antimicrobial regimen was changed to ampicillin ( $2 \mathrm{~g}$ every $4 \mathrm{~h}$ ) and gentamicin on the fifth day of admission. Gentamicin was administered at $120 \mathrm{mg}$ (equivalent to $3 \mathrm{mg} / \mathrm{kg}$ ) for initial loading and then $45 \mathrm{mg}$ (equivalent to $1 \mathrm{mg} / \mathrm{kg}$ ) daily for maintenance. The dose of gentamicin was adjusted appropriately to maintain trough levels of $<1 \mu \mathrm{g} / \mathrm{mL}$. The patient underwent aortic valve replacement (AVR) on the thirteenth hospital day. Vegetations were found to
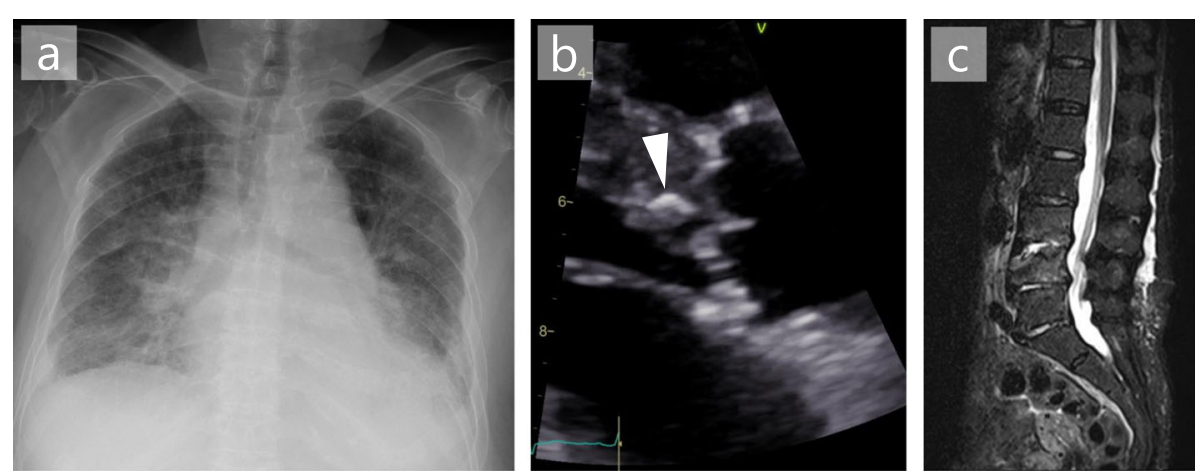

Fig. 1 Diagnostic imaging of Enterococcus casseliflavus endocarditis. a. Chest radiograph showing bilateral interstitial opacities, pleural effusion, and slight cardiac dilatation; b. Transthoracic echocardiogram (parasternal long-axis view) showing aortic valve with vegetation (arrowhead); c. A lumbar MRI STIR image showing osteolytic lesion at the L3/4 level 


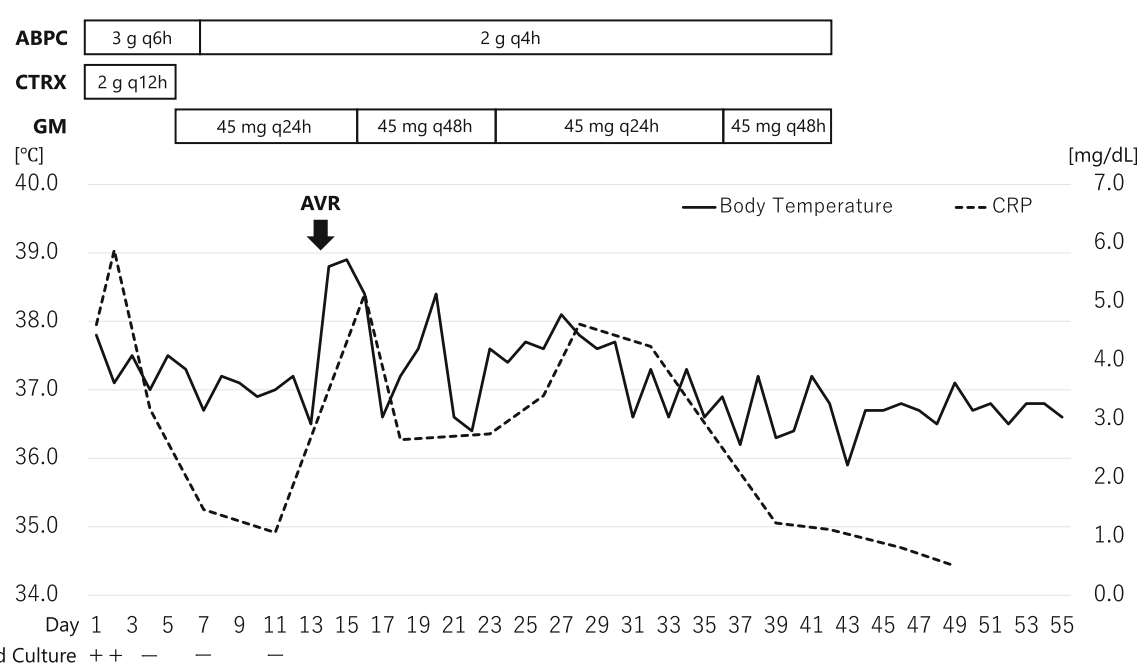

Fig. 2 Timeline of clinical course. AVR: aortic valve replacement; CRP: C-reactive protein; ABPC: ampicillin; CTRX: ceftriaxone; GM: gentamicin; q6h: every $6 \mathrm{~h}$

be attached to the ventricular side of all three aortic valve cusps (Fig. 3a). Histopathological examination of the resected valve showed nodular infiltration of lymphocytes and neutrophils into all the layers, with fibrin precipitation and necrosis and clusters of Gram-positive cocci on the surface, which confirmed the diagnosis of infective endocarditis. The day after AVR, the patient underwent emergency reoperation for cardiopulmonary arrest resulting from cardiac tamponade. The subsequent postoperative course was uneventful. Based on the negative results of both the blood culture taken on the fourth day of admission and excised aortic valve cultures, the patient was administered intravenous ampicillin and gentamicin for 6 weeks. Surveillance blood cultures on days 7,11 , and 27 remained negative. Renal failure and vestibulocochlear dysfunction were not

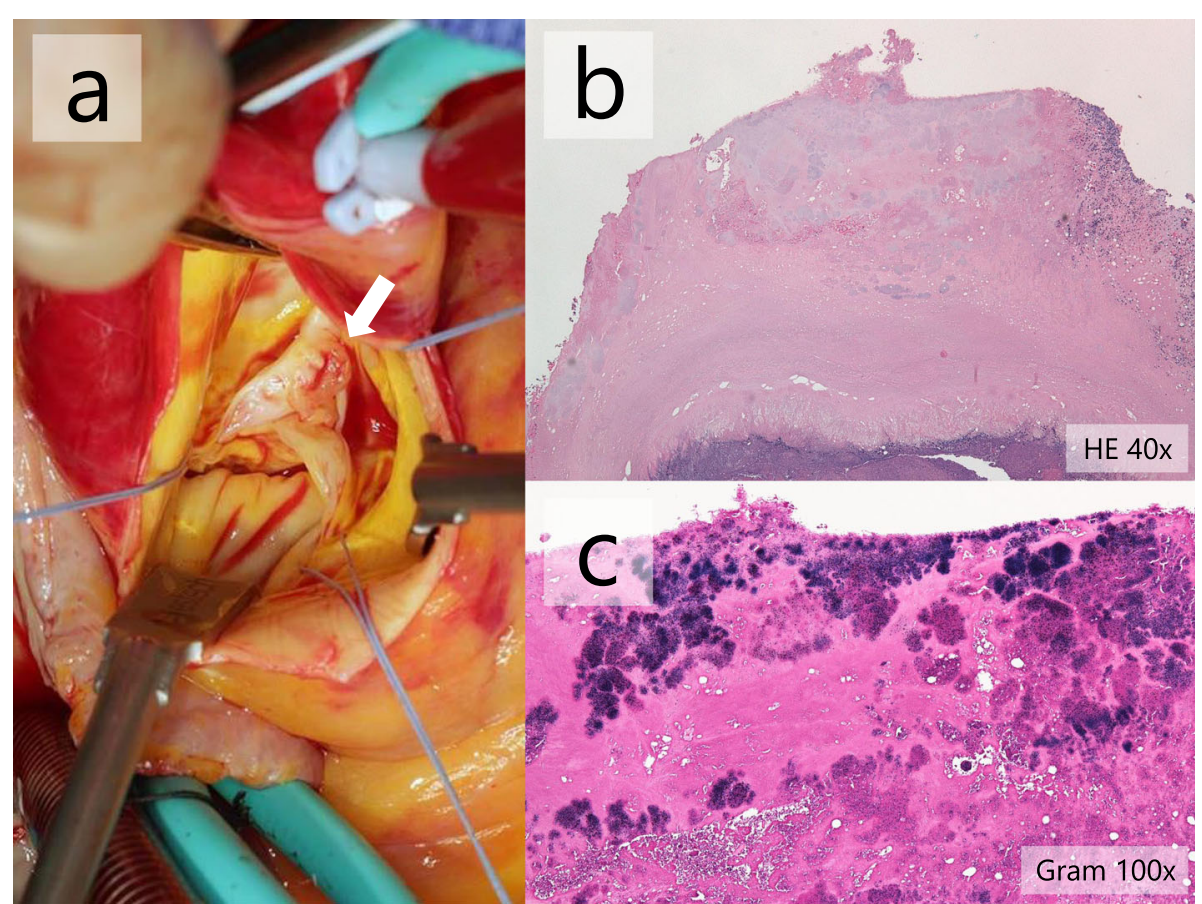

Fig. 3 A picture and histopathological examination of the aortic valve. a. Intraoperative picture of the aortic valve with vegetation (arrow); $\mathbf{b}$. Haematoxylin Eosin staining of the resected aortic valve showing nodular infiltration of lymphocytes and neutrophils into whole layers with fibrin precipitation and necrosis ( $\times 40)$; c. Gram staining showing clusters of Gram-positive cocci on the surface $(\times 100)$ 
observed. The patient was discharged 8 weeks after admission.

\section{Discussion and conclusions}

Enterococci are estimated to cause approximately $10 \%$ of infective endocarditis. E. faecalis and E. faecium account for $95-98 \%$ of enterococcal endocarditis cases $[2,6]$. The risk factors for enterococcal endocarditis include older age, male sex, having an intracardiac device, and infection in a healthcare-associated setting [6]. Treatment of enterococcal endocarditis is challenging because of its resistance to multiple drugs.

E. casseliflavus is known to cause blood stream infection, meningitis, and endophthalmitis in humans [5]. However, there are few reports that E. casseliflavus causes infective endocarditis, and there are no reports on the detailed clinical and treatment course, so the optimal treatment regimen and duration are unknown.

In our case, the patient met the pathological and clinical criteria for infective endocarditis based on the modified Duke criteria [2]. This indicates that E. casseliflavus also causes infective endocarditis.

According to the drug susceptibility pattern of enterococci in the United States, E. casseliflavus is susceptible to penicillin $G$ and ampicillin [7]. It should be noted that $E$. casseliflavus is intrinsically resistant to vancomycin [8]. The vanC-2 gene on the chromosome of $E$. casseliflavus alters the biosynthetic pathway of peptidoglycan, changing the ${ }_{\mathrm{D}}$-Ala- ${ }_{\mathrm{D}}$ Ala end, which is the binding site for vancomycin, to the ${ }_{\mathrm{D}}$ Ala- ${ }_{\mathrm{D}-}$ Ser end [9]. This inhibits vancomycin binding. We should be aware that antimicrobial susceptibility tests of $E$. casseliflavus may report "susceptible" to vancomycin, as the vancomycin resistance resulting from $v a n C$ gene is of a low level. Although aminoglycosides are the cornerstone in the treatment of enterococcal infections, especially in infective endocarditis, approximately $18 \%$ of $E$. casseliflavus are reported to represent high-level resistance to gentamicin [10].

In general, single-agent treatment for enterococcal endocarditis is not recommended because approximately two-thirds of failures occur when penicillin is used as monotherapy [11]. The double- $\beta$-lactam regimen, or a combination of aminopenicillin and third-generation cephalosporin, showed a synergistic effect against $E$. faecalis [12]. This is considered to be caused by the partial saturation of penicillin-binding proteins (PBPs) 4 and 5 by aminopenicillin combined with the total saturation of PBPs 2 and 3 by third-generation cephalosporins. The profile of PBPs in E. casseliflavus is not well understood. Although the double- $\beta$-lactam regimen is one of the promising treatment options for endocarditis caused by $E$. faecalis, its effectiveness has not been proven in endocarditis caused by enterococci other than
E. faecalis [13, 14]. Therefore, we referred to the treatment of endocarditis caused by a closely related species, E. gallinarum. In our search, we discovered five reported cases of infective endocarditis caused by E. gallinarum [15-19]. The treatment regimen was penicillin or ampicillin plus gentamicin in three cases [15-17], vancomycin in one case [18], and unknown in one case [19]. Although E. casseliflavus and E. gallinarum are genetically close and the resistance rate to ampicillin or aminoglycoside is similar, difference in resistance to erythromycin and vancomycin have been reported [20].

Based on the antimicrobial susceptibility pattern of isolated E. casseliflavus and these case reports, we chose ampicillin plus gentamicin. Although it is recommended that gentamicin should be administered in daily multiple divided doses in patients with enterococcal endocarditis [2], we administered gentamicin once daily because our patient had renal impairment. Older age and preexisting renal disease are known to be risk factors for aminoglycoside nephrotoxicity [1]. Our case showed the possibility that some patients with these risk factors could complete the aminoglycoside-containing regimen without developing nephrotoxicity if the dose is appropriately adjusted using therapeutic drug monitoring. Alternative regimens for patients with multiple risk factors of nephrotoxicity include 2-weeks aminoglycoside or double- $\beta$-lactam regimen. However, further investigation is needed on such regimens for patients with endocarditis caused by E. casseliflavus.

According to several guidelines [2, 21], the duration of antimicrobial therapy in native valve enterococcal endocarditis depends on the duration of infection before diagnosis. Patients with $<3$ months' symptom duration can be successfully treated with 4 weeks of therapy, while patients with $\geq 3$ months' symptom duration can be successfully treated with 6 weeks of therapy. Although our patient developed acute respiratory failure, we opted for a 6-week regimen because the lumbago that had been observed for 5 months could have been due to vertebral osteomyelitis following infective endocarditis.

In conclusion, our case demonstrated that E. casseliflavus could cause infective endocarditis, which could be successfully treated with a 6-week regimen of ampicillin and gentamicin in combination with proper surgical treatment.

\section{Abbreviations \\ CCr: Creatinine clearance; MRI: Magnetic resonance imaging; MALDI- TOF: Matrix-assisted laser desorption/ionisation time-of-flight; MS: Mass spectrometry; AVR: Aortic valve replacement; PBP: Penicillin-binding protein}

Acknowledgements

We acknowledge the excellent assistance of the bacterial laboratory staff of Anjo Kosei Hospital. 


\section{Authors' contributions}

NO drafted and prepared the manuscript. NO acquired, analyzed, and interpreted the patient data. NO, TW and ST were involved in the clinical care of the patient. $\mathrm{NO}, \mathrm{DS}, \mathrm{TaH}, \mathrm{KT}$, and ToH edited the manuscript. All authors read and approved the final manuscript.

\section{Funding}

There were no sources of funding used in the conception, composition, editing, or submission of this manuscript.

\section{Availability of data and materials}

Not applicable.

\section{Declarations}

\section{Ethics approval and consent to participate}

Not applicable.

\section{Consent for publication}

Written consent was obtained from the patient for publication of this case report and may be made available upon request.

\section{Competing interests}

The authors declare that they have no competing interests.

\section{Author details}

'Department of Respiratory Medicine, Anjo Kosei Hospital, Anjo-cho Higashi-Hirokute 28, Anjo City, Aichi Prefecture, Japan. ${ }^{2}$ Department of Cardiology, Anjo Kosei Hospital, Anjo-cho Higashi-Hirokute 28, Anjo City, Aichi Prefecture, Japan. ${ }^{3}$ Emergency Department, Anjo Kosei Hospital, Anjo-cho Higashi-Hirokute 28, Anjo City, Aichi Prefecture, Japan. ${ }^{4}$ Department of Infectious Diseases, Anjo Kosei Hospital, Anjo-cho Higashi-Hirokute 28, Anjo City, Aichi Prefecture, Japan.

Received: 27 December 2020 Accepted: 10 May 2021

Published online: 18 May 2021

\section{References}

1. Bennett JE, Dolin R, Blaser MJ. Mandell, Douglas, and Bennett's Principles and Practice of Infectious Diseases. 9th ed. Philadelphia: Elsevier; 2019.

2. Baddour LM, Wilson WR, Bayer AS, Fowler VG, Tleyjeh IM, Rybak MJ, et al. Infective endocarditis in adults: diagnosis, antimicrobial therapy, and Management of Complications: a scientific statement for healthcare professionals from the American Heart Association. Circulation. 2015;132(15): 1435-86. https://doi.org/10.1161/CIR.0000000000000296.

3. Mundt JO, Graham WF. Streptococcus faecium var. casseliflavus, nov. var. J Bacteriol. 1968:95(6):2005-9. https://doi.org/10.1128/JB.95.6.2005-2009.1968.

4. Naser SM, Vancanneyt M, Hoste B, Snauwaert C, Vandemeulebroecke K, Swings J. Reclassification of Enterococcus flavescens Pompei et al. 1992 as a later synonym of Enterococcus casseliflavus (ex Vaughan et al. 1979) Collins et al. 1984 and Enterococcus saccharominimus Vancanneyt et al. 2004 as a later synonym of Enterococcus italicus Fortina et al. 2004. Int J Syst Evol Microbiol. 2006;56(Pt 2):413-6. https://doi.org/10.1099/ijs.0.63891-0.

5. Monticelli J, Knezevich A, Luzzati R, Di Bella S. Clinical management of nonfaecium non-faecalis vancomycin-resistant enterococci infection. Focus on Enterococcus gallinarum and Enterococcus casseliflavus/flavescens. J Infect Chemother. 2018;24(4):237-46. https://doi.org/10.1016/j.jiac.2018.01.001.

6. Chirouze C, Athan E, Alla F, Chu VH, Ralph Corey G, Selton-Suty C, et al. Enterococcal endocarditis in the beginning of the 21st century: analysis from the international collaboration on endocarditis-prospective cohort study. Clin Microbiol Infect. 2013;19(12):1140-7. https://doi.org/10.1111/14 69-0691.12166.

7. Gordon S, Swenson JM, Hill BC, Pigott NE, Facklam RR, Cooksey RC, et al. Antimicrobial susceptibility patterns of common and unusual species of enterococci causing infections in the United States. Enterococcal study group. J Clin Microbiol. 1992;30(9):2373-8. https://doi.org/10.1128/JCM.30. 9.2373-2378.1992

8. Clinical \& Laboratory Standards Institute., "CLSI M100-ED30: 2020 Performance Standards for Antimicrobial Susceptibility Testing, 30th Edition." Wayne.
9. Cetinkaya Y, Falk P, Mayhall CG. Vancomycin-resistant enterococci. Clin Microbiol Rev. 2000;13(4):686-707. https://doi.org/10.1128/CMR.13.4.686.

10. Schouten MA, Voss A, Hoogkamp-Korstanje JA. Antimicrobial susceptibility patterns of enterococci causing infections in Europe. The European VRE study group. Antimicrob Agents Chemother. 1999;43(10):2542-6. https://doi. org/10.1128/AAC.43.10.2542.

11. Murray BE. The life and times of the Enterococcus. Clin Microbiol Rev. 1990; 3(1):46-65. https://doi.org/10.1128/CMR.3.1.46.

12. Mainardi $J$, Gutmann L, Acar JF, Goldstein FW. Synergistic effect of amoxicillin and cefotaxime against Enterococcus faecalis. Antimicrob Agents Chemother. 1995:39(9):1984-7. https://doi.org/10.1128/AAC.39.9.1984.

13. Gavaldà J, Len $O$, Miró JM, Muñoz P, Montejo M, Alarcón A, et al. Brief communication: treatment of Enterococcus faecalis endocarditis with ampicillin plus ceftriaxone. Ann Intern Med. 2007;146(8):574-9. https://doi. org/10.7326/0003-4819-146-8-200704170-00008.

14. Fernández-Hidalgo N, Almirante B, Gavaldà J, Gurgui M, Peña C, de Alarcón A, et al. Ampicillin plus ceftriaxone is as effective as ampicillin plus gentamicin for treating Enterococcus faecalis infective endocarditis. Clin Infect Dis. 2013;56(9):1261-8. https://doi.org/10.1093/cid/cit052.

15. Reid KC, Cockerill FR III, Patel R. Clinical and epidemiological features of Enterococcus casseliflavus/flavescens and Enterococcus gallinarum bacteremia: a report of 20 cases. Clin Infect Diis. 2001;32(11):1540-6. https://doi.org/10.1 086/320542

16. Ortu M, Gabrielli E, Caramma I, Rossotti R, Gambirasio M, Gervasoni C. Enterococcus gallinarum endocarditis in a diabetic patient. Diabetes Res Clin Pract. 2008:81(1):e18-20. https://doi.org/10.1016/j.diabres.2008.03.016.

17. Swampillai J, Liang M, Fisher R, Devlin G. Enterococcus gallinarum causing native valve endocarditis and aorto-atrial fistula: a case report and literature review. Echocardiography. 2012;29(7):873-5. https://doi.org/10.1111/j.15408175.2012.01685.x

18. Dargere S, Vergnaud M, Verdon R, Saloux E, Le Page O, Leclercq R, et al. Enterococcus gallinarum endocarditis occurring on native heart valves. J Clin Microbiol. 2002;40(6):2308-10. https://doi.org/10.1128/JCM.40.6.2308-2310.2 002.

19. Angelos T, Nikolaos S, Nikolaos K, Nektarios P, Evdokia P. A rare case of tricuspid valve endocarditis caused by Enterococcus gallinarum in a patient with recurrent urinary tract infection. Cardiovasc Hematol Disord Drug Targets. 2018;18(2):162-4. https://doi.org/10.2174/1871529X186661803 02113428.

20. Choi SH, Lee SO, Kim TH, Chung JW, Choo EJ, Kwak YG, et. al., "Clinical features and outcomes of bacteremia caused by Enterococcus casseliflavus and Enterococcus gallinarum: analysis of 56 cases.," Clin Infect Dis 2004; 38: 53-61, 1, DOl: https://doi.org/10.1086/380452..

21. Habib G, Lancellotti P, Antunes MJ, Bongiorni MG, Casalta JP, Del Zotti F, et al. 2015 ESC guidelines for the management of infective endocarditis: the task force for the Management of Infective Endocarditis of the European Society of Cardiology (ESC). Endorsed by: European Association for CardioThoracic Surgery (EACTS), the European Association of Nuclear Medicine (EANM). Eur Heart J. 2015;36(44):3075-128. https://doi.org/10.1093/eurheartj/ ehv319.

\section{Publisher's Note}

Springer Nature remains neutral with regard to jurisdictional claims in published maps and institutional affiliations.

Ready to submit your research? Choose BMC and benefit from:

- fast, convenient online submission

- thorough peer review by experienced researchers in your field

- rapid publication on acceptance

- support for research data, including large and complex data types

- gold Open Access which fosters wider collaboration and increased citations

- maximum visibility for your research: over $100 \mathrm{M}$ website views per year

At $\mathrm{BMC}$, research is always in progress.

Learn more biomedcentral.com/submissions 